\title{
Technetium Tc-99m Medronate
}

National Cancer Institute

\section{Source}

National Cancer Institute. Technetium Tc-99m Medronate. NCI Thesaurus. Code C67060.

A radiopharmaceutical containing methylene diphosphonate (medronate; MDP) complexed with the gamma-emitting radionuclide technetium Tc 99m with radioisotopic activity and hydroxyapatite affinity. Upon intravenous administration, skeletal uptake of technetium Tc 99m methylene diphosphonate occurs as a function of skeletal blood flow and osteogenic activity. The MDP moiety of this agent has affinity for hydroxyapatite crystals in bone with abnormal accumulation at sites with increased osteoid mineralization; labeling of MDP with Tc 99m allows scintigraphic imaging of areas of abnormal osteogenesis associated with malignant bone lesions. 